\title{
Is Equality Stable?
}

\author{
By Dilip MoOKHERJEe AND Debraj RAY*
}

Economic inequality is of interest not only at some intrinsic level, but also for its close connections to diverse variables, ranging from economic indicators such as growth rates to sociopolitical outcomes such as collective action and conflict. It is only natural, then, to study the evolution of inequality in an economic system.

It is fair to say that the dominant view on this topic is that inequality is the outcome of a constant battle between convergence and "luck" (Gary Becker and Nigel Tomes, 1979). Current asset inequalities may echo into the future, but their natural tendency is to die out (owing to a convex investment technology). Disparities are only sustained through ongoing stochastic shocks (see also David Champernowne, 1953; Glenn Loury, 1981).

A second approach emphasizes that initial conditions determine final outcomes, owing principally to a nonconvex investment technology (see e.g., Mukul Majumdar and Tapan Mitra, 1982; Abhijit Banerjee and Andrew Newman, 1993; Oded Galor and Joseph Zeira, 1993; Ray and Peter Streufert, 1993). Historical disparities may persist and magnify, if such differences straddle some bifurcation threshold. Inequality is not inevitable in this view: stable steady states with inequality coexist with others that involve perfect equality.

In this paper, we examine a third view which emphasizes an intrinsic tendency of the market mechanism to create inequality. In this approach, economic inequality appears as an inevitable outcome, even if all agents are identical to begin with and even if there is no uncertainty or technological nonconvexity. This view has received attention in Ray (1990), Debasis Bandyopadhyay (1993), Lars Ljungqvist (1993), Scott Freeman (1996),

\footnotetext{
* Mookherjee: Department of Economics, Boston University, 270 Bay State Road, Boston, MA 02215; Ray: Department of Economics, New York University, 269 Mercer Street, New York, NY 10003, and Instituto de Análisis Económico (CSIC), Barcelona, Spain. We thank Kiminori Matsuyama, who encouraged us to write this paper.
}

Kiminori Matsuyama (2001), and Mookherjee and Ray (2001). The basic argument is as follows. Suppose that an economy is populated by several dynasties, each of which allocates resources to current consumption and bequests to descendants. Assume for the moment that the latter consists entirely of educational expenditures preparing children for their chosen professions. Of course, the returns to such professions are endogenous; they depend on the distribution of individuals across different professions.

Now, if several professional categories are necessary, wages must adjust so as to force separation in choices even if all individuals are ex ante identical. To be sure, this "broken symmetry" (Matsuyama, 2002) has no payoff implications for the generation alive today; identical individuals must receive identical payoffs. Starting with the next generation, however, there must be inequality (not just in wages, but in payoffs). There must be individuals in lowpaying professions that involve low training costs, whose parents invested little; and there must be others in high-paying high-trainingcost professions whose parents invested a lot. Once such inequality sets in, it may well magnify. Richer offspring will find it easier to invest in better-paying professions for their children.

Two ingredients are used in this argument. First, credit markets must be missing (or imperfect). Otherwise the necessary finances may be borrowed, and wages net of costs must be equalized over all professions. However, the assumption that parents cannot borrow against their children's future earnings seems innocuous enough. Second, parents cannot make financial bequests to supplement or substitute for educational expenditures. Such bequests could conceivably neutralize earnings inequality. This motivates the question: When might financial bequests compensate for earnings inequality in steady state? Moreover, starting from perfect equality, will equality be preserved thereafter, or will inequality emerge and persist? We discuss an extended example from an ongoing research project. 


\section{A Dynastic Model}

Let $h$ denote an occupation or profession. A collection of population weights $\boldsymbol{\lambda}=\{\lambda(h)\}$ is an occupational distribution. Alternatively, $\boldsymbol{\lambda}$ is just a bundle of inputs, which produces a single final good using a convex constant-returns-toscale technology. Measured in units of this good, occupation $h$ costs $x(h)$ to acquire. We assume that there are occupations $h$ and $h^{\prime}$ with $x(h)=0$ and $x\left(h^{\prime}\right)>0$.

Let $w(h)$ be the wage of occupation $h$. The collection $\mathbf{w}=\{w(h)\}$ is a wage function. Under fairly innocuous smoothness conditions, for each occupational distribution $\boldsymbol{\lambda}$ there is a unique "supporting" wage function $\mathbf{w}$ (i.e., $\boldsymbol{\lambda}$ maximizes profits given w). Conversely, every $\mathbf{w}$ admits some shift $\mathbf{w}+\mathbf{k}$ corresponding to which a unique profit-maximizing occupational distribution $\boldsymbol{\lambda}$ exists. We retain these assumptions.

Suppose that each dynasty has a single individual at any date. She has resources (or wealth) $W$ from two sources: a market-determined wage that depends on her profession, and financial assets that represent the (interest-updated) result of any financial bequest. In turn, she allocates $W$ to current consumption $c$, a financial bequest $b$, and training costs $x(h)$ for her child's future occupation $h$. We assume that financial bequests yield some exogenous rate of interest $r$, perhaps the going rate on a world financial market. ${ }^{1}$ As already noted, we impose the condition that $b \geq 0$; the parent cannot borrow against the child's future assets.

The resulting wealth of the child will be $W^{\prime} \equiv$ $(1+r) b+w^{\prime}(h)$, where $\mathbf{w}^{\prime}$ is next generation's wage function. Assume that a parent derives utility from her own consumption and the wealth of her child, and write this as $u(c)+$ $v\left(W^{\prime}\right)$, where $u$ and $v$ are increasing, smooth, strictly concave utility indicators. This is what one might call a warm-glow specification. ${ }^{2}$

We now define an equilibrium. Initially, each dynasty $i$ is "allocated" an occupation and fi-

\footnotetext{
${ }^{1}$ One can allow for a closed market in which the interest rate is determined endogenously, but in the interests of brevity we do not do that here.

${ }^{2}$ We eschew dynastic preferences here for simplicity of exposition, but we address this case in our general research project.
}

nancial assets. An equilibrium describes an entire sequence of such allocations. At each date, the allocation determines an occupational distribution $\boldsymbol{\lambda}_{t}$, as well as the (supporting) wage function $\mathbf{w}_{t}$. Each individual must find her decisions to be optimal, given her budget. More formally, dynasty $i$ 's wealth at date $t$ will be given by $W_{t}(i)=b_{t-1}(i)(1+r)+w_{t}\left(h_{t}(i)\right)$. Given this wealth, $i$ chooses $\left(c_{t}, b_{t}, h_{t+1}\right)$ to maximize

(1) $u\left(c_{t}\right)+v\left(b_{t}(1+r)+w_{t+1}\left(h_{t+1}\right)\right)$

subject to

$$
c_{t}+x\left(h_{t+1}\right)+b_{t}=W_{t}(i) .
$$

In turn, these choices must aggregate to the economy-wide distribution at every date.

An equilibrium is a steady state if the joint distribution of financial wealth and occupations (and therefore the wage function) is unchanged over time. In principle, a steady state could be associated with wealth changes over time within dynasties, but a "single-crossing argument" establishing the monotonicity of parental bequests in wealth rules this out. A constant distribution implies zero wealth mobility (Mookherjee and Ray, 2001).

In what follows, we assume that all professions are occupied in equilibrium. This restriction, while not necessary for the results, simplifies the exposition greatly. ${ }^{3}$

\section{Is Equality Stable?}

\section{A. Preliminaries}

To develop useful notation, consider a benchmark model with no choice of occupations. There is a constant wage $w$ at every date, and only financial bequests are permitted. Then, given resources $W$, an individual will choose $b$ to maximize $u(W-b)+v\left(W^{\prime}\right)$, where $W^{\prime} \equiv$ $[1+r] b+w$. Define $\Psi(W, w)$ to be the resulting choice of $W^{\prime}$.

Of course, $\Psi$ is a nondecreasing function of $W$. To illustrate using an example with constant-

\footnotetext{
${ }^{3}$ The existence of some occupational diversity will suffice, though we indicate an important qualification later.
} 
elasticity preferences, assume that $v$ equals $\delta u$ for some discount factor $\delta$ and $u(c)=c^{1-\sigma /}$ $(1-\sigma)$ for some $\sigma>0$. Then,

$$
\Psi(W, w)=\frac{(1+r) \rho}{1+\rho+r} W+\frac{\rho}{1+\rho+r} w
$$

if $\rho W \geq w$, and equals $w$ otherwise, where $\rho \equiv$ $[\delta(1+r)]^{1 / \sigma}$.

In addition, if the persistence coefficient, defined by the increase in next period's assets following a unit change in assets today, is bounded above by unity, then for any given $w$, $\Psi(\cdot, w)$ intersects the $45^{\circ}$ line once and only once. This condition plays a central role in conventional models of convergence (e.g., Becker and Tomes, 1979) and is supported by a substantial empirical literature (see e.g., Casey Mulligan, 1997; Samuel Bowles and Herbert Gintis, 2001). We impose it here as well and refer to it as the imperfect persistence assumption. In the constant-elasticity example, imperfect persistence is satisfied if and only if

$$
\rho \equiv[\delta(1+r)]^{1 / \sigma}<1+\frac{1}{r} .
$$

Under this assumption, the policy function precipitates a unique limit wealth $\Omega(w)$. In the example with (3) satisfied, $\Omega(w)=w$ if $\rho \leq 1$, and equals $(\rho /[1-r(\rho-1)]) w$ otherwise.

\section{B. Steady States with Inequality}

Consider a special wage function $\mathbf{w}^{*}$ such that $w^{*}(h)-w^{*}\left(h^{\prime}\right)=(1+r)[x(h)-$ $\left.x\left(h^{\prime}\right)\right]$ for every pair of occupations $h$ and $h^{\prime}$, and shifted suitably so that it can serve as a supporting wage function for some occupational distribution. Because the technology is constant returns to scale, there is, of course, a unique wage function of this form. Let $w^{*}$ be the lowest wage in $\mathbf{w}^{*}$, and $\bar{w}^{*}$ be the highest wage.

PROPOSITION 1: As long as

$$
\bar{w}^{*}>\Omega\left(\underline{w}^{*}\right)
$$

every steady state must involve (utility) inequality. If (4) fails, a steady state with per- fect equality exists and must display the wage function $w^{*}$.

This proposition is extremely general in that it relies on very few restrictions on preferences and technology. We sketch the argument briefly. In an equal steady state (with all professions occupied), the rate of return on education must everywhere equal $r$ : it must obviously be at least $r$ everywhere, and if it strictly exceeds $r$ somewhere, some occupations with lower training costs will not be chosen. This shows that an equal steady-state wage function must be given by $\mathbf{w}^{*}$. In addition, earning differentials must be perfectly offset by differences in financial bequests. If all households have the same resources $W$, someone earning $w$ must receive a financial bequest $b(w)=(W-w) /$ $(1+r)$. The smallest bequest must be received by the individual with the largest earnings. Since bequests must be nonnegative, $W$ cannot fall short of $\bar{w}^{*}$. But $W$ is just $\Omega\left(\underline{w}^{*}\right)$, because all rates of return equal $r$. Hence, condition (4) must be violated.

Conversely, if (4) fails, equal steady states exist. Select the wage function $\mathbf{w}^{*}$, and spread the labor force out over different occupations in the proportions demanded by $\mathbf{w}^{*}$. Allow all parents to make bequests that will ensure that their children attain the same wealth $\Omega\left(\underline{w}^{*}\right)$. The failure of (4) tells us that such bequests will indeed be willingly made and will compensate completely for earning differences, resulting in perfect equality in consumption and utilities. To be sure, such steady states may coexist with others that display inequality, though this is unlikely to happen with a sufficiently rich professional structure (see Section II-C).

What sorts of configurations favor (4)? Essentially these require that the bequest motive not be so strong as to overwhelm all earning differences. For instance, if $\delta(1+r) \leq 1$ in the constant-elasticity case, $\Omega(w)$ must equal $w$, and so (4) must hold. Of perhaps greater interest is the fact that (4) applies to economies with a wide variety of occupations or, more precisely, to occupational structure that exhibit large differences in training costs. In such economies, equilibrium earnings differentials will be too wide to be spanned by financial bequests. Likewise, equality is less likely to be sustainable in poor countries, for the imperfect-persistence 


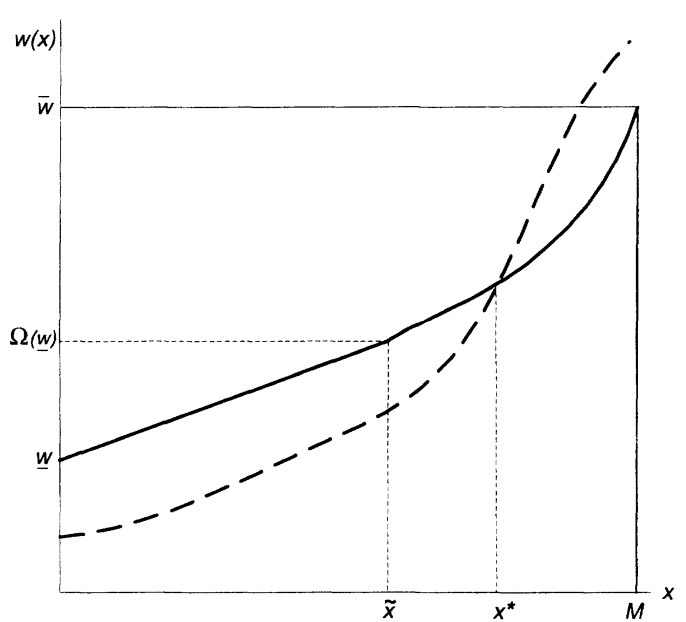

Figure 1. A Steady-State Wage Function

assumption implies that uniform increases in wages will result in more than proportionate increases in the corresponding wealth levels, making it more likely that (4) will hold. On the other hand, higher growth rates may be less conducive to equality. For instance, suppose that there is Hicks-neutral technical progress so that in a steady state, all wages grow at the same rate (given some occupational distribution). With faster growth in wages, bequest levels will be reduced (though they will of course grow at the same rate as wages in steady state). This increases the possibility that a condition analogous to (4) will hold, and provides a novel connection between growth and inequality.

\section{Many Occupations}

Consider the special case of a "rich" set of occupations. This case is especially important, as it permits "small" movements in occupational structure at all cost levels and therefore removes the indivisibilities built in by assumption in many existing models (see the discussion in Mookherjee and Ray [2001]).

Assume a continuum of occupations, with training costs in some interval $[0, M]$. Figure 1 depicts a steady-state wage function with the lowest wage equal to $\underline{w}$. Across occupations with wages between $\underline{w}$ and $\Omega(\underline{w})$, wages must be linear in costs with slope $(1+r)$, for individuals will climb to wealth $\Omega(\underline{w})$ on the strength of financial bequests alone. If, in this range, some occupation $h$ affords a higher marginal return than the financial rate, some set of professions below $h$ must remain unoccupied.

Define $\tilde{x}$ by $w(\tilde{x})=\Omega(\underline{w})$. (There may not exist such a point, in which case the steady state involves perfect equality.) Now, the financial rate of return alone will be insufficient to maintain individuals beyond $\tilde{x}$. To encourage the settlement of such occupations, the rate of return on occupational choice must depart from the financial rate at this point. This departure must create inequality: dynasties in "higher" occupations will enjoy strictly higher lifetime utility than their counterparts below $\tilde{x}$.

Notice that both financial and educational bequests are made at the bottom of the occupational ladder, in the region between 0 and $\tilde{x}$. As we move into the higher-occupation categories, financial bequests are apparently shut down, and all intergenerational transfers are made via educational choices. ${ }^{4}$ One should be careful with this interpretation. An "occupation" may well be an financial category with setup costs. With this broad interpretation, financial bequests (at higher rates of return than $r$ ) may coexist with educational choices as we move beyond $\tilde{x}$.

The continuum structure displays an interesting feature: the steady state is unique. ${ }^{5}$ To see this, Figure 1 depicts (by way of contradiction) a second hypothetical steady state as a dotted line. Note that the two wage functions must cross; otherwise, by constant returns to scale, one of them cannot support profit-maximization. Suppose that the two functions intersect at $x^{*}$. As far as an individual with wealth $w\left(x^{*}\right)$ is concerned, the original steady-state function encourages her to choose a total wealth of $w\left(x^{*}\right)$ for her child as well. But then at the second steady state, she must want to move her descendant strictly upward in wealth space, a contradiction to the zero-mobility property of steady states.

\footnotetext{
${ }^{4}$ In part, this observation hinges on the richness of the set of occupations. If there are "gaps" between occupations, some financial bequests may be observed in this region as well.

${ }^{5}$ This result does depend on the postulate that all professions are occupied. If there are "gaps" in equilibrium occupational structure, multiple steady states may exist.
} 
Notice as a corollary that if (4) fails, then equality is the unique steady-state outcome. ${ }^{6}$

\section{Equilibrium Dynamics}

We now turn to the question of dynamics. The basic ideas are simple, though the details are complicated and thus suppressed here. A distribution of wealth (past bequests plus current income) prevails at any date; this will map into a distribution of wealth for the next generation. Of course, the analysis will be different depending on whether condition (4) holds or fails, and in addition there are several different kinds of initial conditions to consider. We report on a single case, but one that holds particular interest. We assume that initial wealth is perfectly equally distributed, yet we suppose that a steady state is incompatible with perfect equality [i.e., that (4) holds].

Begin, then, with a single wealth level which we shall call $W_{0}$, commonly held by every member of generation 0 . The key to understanding the dynamics is the following simple but powerful observation.

Observation 1: Suppose that next period's wage function is given by $\mathbf{w}_{1}$, with lowest wage $\underline{w}_{1}$. Let $W_{1} \equiv \Psi\left(W_{0}, \underline{w}_{1}\right)$. Then for every $x$ such that $w_{1}(x) \leq W_{1}$, it must be the case that $w_{1}(x)=\underline{w}_{1}+(1+r) x$.

This follows from the argument described in Section II-C: the rate of return on educational investment must equal $r$ over the entire range spanned by financial bequests for any given occupation. Observation 1 has an interesting corollary.

Observation 2: For any $N$, there exists a threshold such that, starting from any equal initial wealth above this threshold, there is perfect equality for at least $N$ generations.

To see this, recall the wage function $w^{*}$ constructed to state Proposition 1 . For any $N$, define a threshold (call it $\tilde{W}$ ), such that if $W_{0} \geq \tilde{W}$,

\footnotetext{
${ }^{6}$ If the number of occupations is finite, there may be multiple steady states. For a fuller account of the connection between multiplicity of steady states and richness of occupational structure, see Mookherjee and Ray (2001).
}

then $\Psi^{(N)}\left(W_{0}, \underline{w}^{*}\right) \geq \bar{w}^{*}$, where $\Psi^{(N)}$ is the function $\Psi$ iterated $N$ times. In words, we choose an initial wealth high enough so that $N$ iterations will not suffice to bring wealth down to $\bar{w}^{*}$, in the pure bequest model with baseline wage $\underline{w}^{*}$. If the wage function for the next $N$ periods is given by $\mathbf{w}^{*}$, this is perfectly consistent with equilibrium behavior for those $N$ periods. All occupations are equally valuable, so individuals are indifferent over these choices. Moreover, there will be full equality over this epoch.

Observation 1 implies that this is the only possible outcome for the first $N$ periods. Any other candidate wage function would have to exhibit a return of $r$ over occupations in which the wage fell short of wealth. This implies right away that no other equilibrium wage function can exist with the same starting wage $\underline{w}^{*}$. Using Observation 1 again and employing an argument similar to that used to establish uniqueness in Section II-C, we may also rule out any candidate wage function with a different starting wage than $\underline{w}^{*}$.

Thus, perfect equality can prevail for a substantial number of periods. However, if (4) holds it cannot prevail forever. Because $\Omega\left(\underline{w}^{*}\right)<\bar{w}^{*}$, there must eventually come a date $T$ when the recursion $\psi^{(T)}\left(W_{0}, \underline{w}^{*}\right)$ dips below $\bar{w}^{*}$. At this stage, the symmetry of equilibrium is broken, and the economy must depart from the wage function $\mathbf{w}^{*}$. If not, all occupations with wages that exceed $\psi^{(T)}\left(W_{0}, \underline{w}^{*}\right)$ would remain unoccupied. This cannot be: the wages of such occupations must rise, yielding rates of return that exceed their counterpart on financial bequests. For all other occupations, Observation 1 is applicable in full force, and the occupational rate of return remains anchored to the financial rate.

Figure 2 describes the resulting "distortion" in the wage function. The diagram displays $N$ initial periods in which the wage function $\mathbf{w}^{*}$ prevails, and there is no inequality. At date $N$, wealth dips into the support of $\mathbf{w}^{*}$, and no occupation more expensive than $x_{N}$ can be supported under the old rates of return. The economy must react by lowering the wages of all occupations below $x_{N}$, and by raising the rates of return to all other occupations. These higher rates encourage the acquisition of such professions and in so doing must generate inequality. 


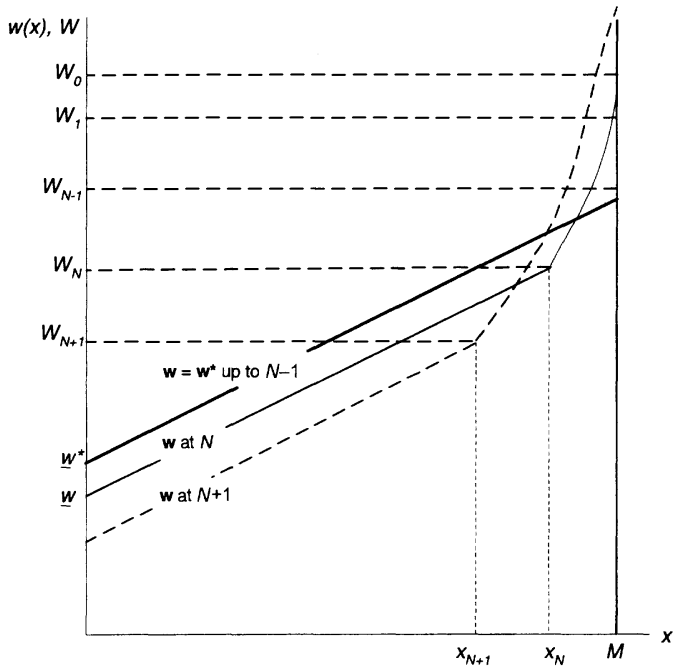

FiguRE 2. SYMMETRY-BREAKING ALONG EQUilibrium PathS

Of course, all generation- $N$ individuals are still indifferent among the various choices; but this is the last generation for which all payoffs are equal. The higher rates of return on the more expensive occupations must inevitably result in inequality among the next generation.

Once such inequality sets in, it will not go away. Familiar single-crossing arguments guarantee that descendants of higher-wealth individuals must occupy the richer professions and receive higher payoffs. The subsequent dynamics are complicated by the fact that the wealth distribution is no longer degenerate. In the special case where there are just two occupations (involving different training costs), it can be shown that the economy converges to an unequal steady state, with inequality rising over time. Moreover, the rise in inequality is augmented in the presence of financial bequests: it turns out that individuals in the unskilled occupation at any date are less wealthy than their parents and make smaller financial bequests to their children than they received.

In the continuum case, the wealth distribution at any date must retain a mass point at its lower bound, and it is this mass point that will be spread over all the "low" occupations, which continue to bear the financial rate of return $r$. In the relatively "high" occupations, the rate of return will continue its departure from $r$, attracting more individuals into this zone.
Figure 2 illustrates this with yet another iteration for date $N+1$. The new wage function is given by the dashed curve. It must be linear (with slope $1+r$ ) up to the new threshold $x_{N+1}$, and then it rises even more steeply than before, intersecting both the previous wage functions from below. This rise induces some fresh symmetry-breaking, as new dynasties from the "cheap" occupations seek the higher rates of return. If this process converges (a subject of our current research), it must be to precisely the steady state we have described earlier. At this steady state, there is a mass point of individuals with identical wealth, and among such individuals there is a simple trade-off between occupational choice and financial bequests, among which they are indifferent. However, there will also be a positive measure of individuals arrayed over varying levels of wealth (and utility).

\section{Concluding Remarks}

We have outlined an approach to studying the evolution of economic inequality. In this approach, the presence of diversity of necessary occupations plays a crucial role. We show that, under fairly general conditions, ex ante identical individuals must behave in a nonsymmetric way, because different professional categories must be occupied for the economy to function. In itself, this is not "payoff-relevant" because the descendants of low-paying occupations can conceivably be compensated by financial bequests left by their parents. This requires a sufficiently strong bequest motive relative to the range of earning differentials, which is unlikely in economies with diverse occupational structure, with low levels of wages, or with high rates of wage growth. When the bequest motive is not so strong, economic inequality will eventually tend to emerge and persist, even if all households start perfectly equal.

\section{REFERENCES}

Bandopadhyay, Debasis. "Distribution of Human Capital, Income Inequality, and the Rate of Growth." Ph.D. dissertation, University of Minnesota, 1993.

$\rightarrow$ Banerjee, Abhijit and Newman, Andrew. "Occupational Choice and the Process of Develop- 
ment." Journal of Political Economy, April 1993, 101(2), pp. 274-98.

Becker, Gary and Tomes, Nigel. "An Equilibrium Theory of the Distribution of Income and Intergenerational Mobility." Journal of Political Economy, December 1979, 87(6), pp. 1153-89.

Bowles, Samuel and Gintis, Herbert. "The Inheritance of Economic Status: Education, Class and Status," in N. J. Smelser and P. B. Baltes, eds., International encyclopedia of the social and behavioral sciences, Vol. 6. Oxford, U.K.: Elsevier, 2001, pp. 4132-41.

$\rightarrow$ Champernowne, David. "A Model of Income Distribution.” Economic Journal, June 1953, 63(250), pp. 318-51.

Freeman, Scott. "Equilibrium Income Inequality among Identical Agents." Journal of Political Economy, October 1996, 104(5), pp. 1047-64.

Galor, Oded and Zeira, Joseph. "Income Distribution and Macroeconomics." Review of Economic Studies, January 1993, 60(1), pp. 35-52.

$\rightarrow$ Ljungqvist, Lars. "Economic Underdevelopment: The Case of Missing Market for Human Capital." Journal of Development Economics, April 1993, 40(2), pp. 219-39.

$\rightarrow$ Loury, Glenn. "Intergenerational Transfers and the Distribution of Earnings." Econometrica, July 1981, 49(4), pp. 843-67.

$\rightarrow$ Majumdar, Mukul and Mitra, Tapan. "Intertemporal Allocation with a Non-convex Technology: The Aggregative Framework." Journal of Economic Theory, June 1982, 27(1), pp. 101-36.

Matsuyama, Kiminori. "Financial Market Globalization and Endogenous Inequality of $\mathrm{Na}$ tions." Mimeo, Northwestern University, 2001.

"Explaining Diversity: SymmetryBreaking in Complementarity Games." American Economic Review, May 2002 (Papers and Proceedings), 92(2), pp. 241-46.

Mookherjee, Dilip and Ray, Debraj. "Persistent Inequality." Mimeo, Boston University, 2001.

Mulligan, Casey. Parental priorities and economic inequality. Chicago: University of Chicago Press, 1997.

Ray, Debraj. "Income Distribution and Macroeconomic Behavior." Mimeo, Boston University, 1990.

$\rightarrow$ Ray, Debraj and Streufert, Peter. "Dynamic Equilibria with Unemployment Due to Undernourishment." Economic Theory, January 1993, 3(1), pp. 61-85. 